\title{
Tuning of diatonic scales by violinists, pianists, and nonmusicians
}

\author{
FRANZ LOOSEN \\ University of Leuven, Leuven, Belgium
}

\begin{abstract}
The present study shows that playing a particular musical instrument influences tuning preference. Violinists $(n=7)$, pianists $(n=7)$, and nonmusicians $(n=10)$ were required to adjust three notes ( $\mathrm{E}$, $\mathrm{A}$, and B) in computer-generated, eight-tone ascending and descending diatonic scales of C major. The results indicated that (1) violinists set the three tones closer to Pythagorean intonation than do pianists $(p<.01)$, (2) pianists fit closest to equal-tempered intonation $(p<.01)$, and (3) nonmusicians do not show any preference for a specific intonation model. These findings are consistent with the view that tuning preference is determined by musical experience more than by characteristics of the auditory system. The relevance of these results to theories of cultural conditioning and assessment of tonal perception is discussed.
\end{abstract}

In this study, the relation between different kinds of musical experience and tuning performance was determined. Violinists, pianists, and nonmusicians were invited to adjust three tones in computer-generated, eighttone ascending and descending diatonic scales of C major. It was expected that (1) the violinists would fit Pythagorean intonation, (2) the pianists would fit equaltempered intonation, and (3) the nonmusicians, who had no particular musical experience, would show no bias toward any intonation model.

Traditionally, attention has been given to (1) the intonation used by performing musicians, (2) the intonation preferred by listeners in forced-choice experiments with tonal sequences in different intonations, and (3) the intonation used by subjects adjusting isolated musical intervals (Allen, 1967; Barbour, 1951/1972; Cornu \& Mercadier, 1872; Corso, 1954a, 1954b; Devie, 1990; Ellis, 1954; Geringer, 1978; Greene, 1937; Lloyd \& Boyle, 1963; Loosen, 1993; Mathews \& Sims, 1981; Nickerson, 1949; Partch, 1949; Rakowski, 1976; Roberts \& Mathews, 1984; Small, 1937; Vos, 1982; Vos \& van Vianen, 1985; Ward, 1970; Ward \& Martin, 1961). The general trend of the results of all these experiments was for the subjects to "compress" smaller intervals and "stretch" wider intervals relative to equal-tempered intonation (the present standard in Western music). ${ }^{1}$

In some studies, musically experienced subjects have been compared with inexperienced subjects (e.g., Algom

The author is indebted to Noel Bovens, Rik Delabastita, Gabriel Forrez, Donald Leenknecht, and Jan Wouters for technical support, and to W. Jay Dowling, Neil Macmillan, C. Douglas Creelman, Bruno H. Repp, and W. Dixon Ward for constructive comments on an earlier version of the manuscript. The author also wishes to thank Monique Lioen and John Drewery for their aid in the preparation of the article. Thanks are also due the subjects, who gave their full cooperation in the experiment. Requests for reprints and correspondence concerning this paper should be addressed to F. Loosen, Department of Psychology, University of Leuven, 102 Tiensestraat, B-3000, Leuven, Belgium.
\& Marks, 1984; Elliot, Platt, \& Racine, 1987; Platt \& Racine, 1985; Siegel \& Siegel, 1977a; Walker, 1987). As might be expected, in the case of musical stimuli, the performance of experienced subjects is always superior to that of inexperienced subjects.

So far, no attention has been given to whether playing a particular musical instrument influences tuning preferences after a number of years. The only authors who have done work related to this question are Platt and Racine (1985), who compared the accuracy with which three groups of subjects adjusted a comparison tone with sine-wave and string-timbre standard tones of different frequencies. The subjects were "tuners," who were experienced on an instrument they regularly tuned, "nontuners," who had had experience on an instrument that did not involve tuning, and "inexperienced," who had received less than 1 year of training on any musical instrument. The results indicated that the effects of experience were attributable to musical experience in general, rather than to tuning experience per se.

Musicians frequently believe that playing an instrument that has a tone-generating mechanism that is related to a particular intonation model causes performers to prefer that intonation model. From this perspective, it may be expected that violinists prefer Pythagorean intonation because both the violin and the Pythagorean model rely on perfect fifths (i.e., intervals between two frequencies having a ratio of $3: 2$ ); the open strings of a violin are tuned by perfect fifths, and the intervals in Pythagorean intonation are derived from a circle of perfect fifths. Following the same reasoning, it may be expected that pianists should prefer equal-tempered intonation, because they are used to an instrument that is tuned in approximately the same way. ${ }^{2}$ Although such assertions appear plausible on the basis of what is known about habit formation and perceptual learning, they have little meaning until the relation between musical experience and intonation preference has been established empirically. 


\section{METHOD}

\section{Subjects}

The subjects were 7 professional violinists ( 4 males and 3 females), 7 professional pianists ( 4 males and 3 females), and 10 musically inexperienced subjects ( 5 males and 5 females), referred to here as nonmusicians. The ages of the musicians ranged from 25 to 31 years, and the ages of the nonmusicians varied from 20 to 23 years. All the musicians were members of an orchestra (or a chamber music ensemble) and were teachers in an academy of music. None of the violinists or pianists played any other instrument professionally. The nonmusicians were graduate students who had never practiced a musical instrument or studied music formally. The subjects were screened using a Békésy-type audiometer (Brüel \& Kjaer, Model 1800). All the subjects showed "normal" hearing, in that they tested at $20 \mathrm{~dB} \mathrm{HL}$ or better in both ears at all test frequencies. All the subjects were unaware of the objective of the experiment, and none of them had had any experience with tonal experiments prior to this study. They participated voluntarily without monetary compensation.

\section{Stimuli and Apparatus}

The tones were band-limited pseudosawtooth waves, generated by additive synthesis of the fundamental and the first eight harmonics with amplitudes according to

$$
p(t)=\sum_{n=1}^{9} \frac{1}{n} \sin \left(2 n \pi f t-\phi_{n}\right)
$$

This resulted in a tone with a spectral envelope slope of $-6 \mathrm{~dB} /$ octave. The phases $\left(\phi_{n}\right)$ of the individual harmonics were randomly set according to a uniform distribution in the interval $[0, \pi / 36]$. As a result, the waveforms of repeated generations of the same note, although having the same spectral envelope, varied (as in actual performance) slightly. The tones had amplitude envelopes of $800-\mathrm{msec}$ duration, including linear rise and fall times of 30 and $20 \mathrm{msec}$, respectively. Transients were not audible, and adjacent tones were separated by a $20-\mathrm{msec}$ silent interval. The acoustical parameters resulted in a musical sound with a timbre that could crudely be described as a bland clarinet timbre.

The tones were generated by an electronic system consisting of nine digital oscillators. Each oscillator was an eight-bit digital-toanalog converter, controlled by a 256 -byte waveform table at a sample rate of $31.25 \mathrm{kHz}$ with 1 -byte amplitude and 2-byte frequency specifications. The outputs of the oscillators were summed and lowpass filtered for smoothing by a Krohn-Hite filter, Model $330 \mathrm{~N}$. The cutoff frequency of the filter was approximately $5 \mathrm{kHz}$. The resulting signal passed through a buffer amplifier to a high-fidelity audio preamplifier (Klein +Hummel, Model SSV) and was subsequently played through a high-quality studio loudspeaker system (Klein +Hummel, Model OY) with an incorporated amplifier. The loudspeaker system had an almost perfectly flat frequency response between $100 \mathrm{~Hz}$ and $14 \mathrm{kHz}( \pm 2 \mathrm{~dB}$ SPL).

The loudness of the tones was not controlled because scaling data were not available for the tones used in the present study. The sound pressure level in the test room was not measured, but was set at a comfortable listening level-estimated to be about $70 \mathrm{~dB}$ at the subjects' ears. Experimental control and data acquisition were performed by a Rockwell AIM-65 computer.

\section{Stimulus Scales}

The stimulus scales were ascending and descending diatonic scales of $C$ major $\left(C_{4}-C_{5}\right)$ in which $E_{4}, A_{4}$, and $B_{4}$ were out of tune. The scale of $\mathrm{C}$ major was chosen because of its pervasive character (see Burns \& Ward, 1982, for a thorough discussion of arguments). More specifically, E, A, and B were set out of tune because they have the largest differences in the musical scales that were studied: the equal-tempered, the Pythagorean, and the just intoned (see Table 1). ${ }^{3}$

The fundamental frequencies of the fixed notes (i.e., the notes that were not adjustable by the subjects) were defined by the normative frequencies in (1) a Pythagorean scale, where $A_{4}=440 \mathrm{~Hz}$ (Type la stimulus scale); (2) a just intonation scale, where $\mathrm{A}_{4}=$ $440 \mathrm{~Hz}$ (7ype Ib stimulus scale); or (3) an equal-tempered scale, where $\mathrm{A}_{4}=440 \mathrm{~Hz}$ (Type 2 stimulus scale) (see Table 2).

The fundamental frequencies of mistuned notes varied randomly from stimulus scale to stimulus scale. In the Type $1 \mathrm{a}$ and Type $1 \mathrm{~b}$ stimulus scales, the frequencies of flat notes were randomly set according to a uniform distribution ranging from 30 to 50 cents below the geometric mean of the normative frequencies for the corresponding notes in Pythagorean and just intonations. The frequencies of sharp notes were defined analogously. In the Type 2 stimulus scales, the frequencies of flat (sharp) notes were 30 to 50 cents below (above) equal-tempered intonation. Approximately $50 \%$ of the mistuned notes were too low, and $50 \%$ were too high when compared with the respective scale models.

In the strict sense, only the Type 1 stimulus scales could be adjusted to a sequence of tones that fit the Pythagorean or the just intonation perfectly, and only the Type 2 stimulus scales could be adjusted to a sequence that fit the equal-tempered scale perfectly. Perceptually, however, each stimulus scale could be adjusted perfectly to each intonation model because there is no evidence that listeners could hear the 2- and 4-cent differences between the corresponding intervals between fixed notes in the three stimulus scales (Sharf \& Buus, 1986). Hence, from a perceptual point of view, the three types of stimulus scales could be considered as identical musical frames.

\section{Procedure}

Each subject was tested individually in a sound-attenuating room measuring about $4 \times 4 \mathrm{~m}$. All apparatus was set up outside the room. The subject was seated comfortably about $2 \mathrm{~m}$ in front of the loudspeaker, which presented both the tape-recorded instructions and the computer-generated tonal stimuli. The subjects were instructed that this was an experiment in tuning notes of a scale. For the nonmusicians, the term musical scale was paraphrased as "the sequence do, re, mi, fa, sol, la, ti, do." A hand-held unit, containing 10 push buttons, was used by the subject to call up and adjust the stimulus scales. Since each subject adjusted four ascending and four descending scales of each type of stimulus scale, each made 24 tuning adjustments ( 8 under each stimulus scale). The presentation order of the scales was randomized between and within subjects. The first scale was always ascending.

Notes that were out of tune could be adjusted over a range of -200 to +200 cents of the starting frequency. The order in which the notes were adjusted could be chosen freely by the subjects. Furthermore, they could return to an already partially adjusted note for further corrections at any time by using one of the three "note selection" buttons (labeled E, A, or B). The response unit

Table 1

Differences (in Cents) Between Pythagorean (P), Just (J), and Equally Tempered (T) Intonations in the Diatonic Scale of C Major

\begin{tabular}{crrr}
\hline Note & T-J & T-P & P-J \\
\hline C & 0 & 0 & 0 \\
D & -4 & -4 & 0 \\
E & +14 & -8 & -22 \\
F & +2 & +2 & 0 \\
G & -2 & -2 & 0 \\
A & +16 & -6 & -22 \\
B & +12 & -10 & -22 \\
C & 0 & 0 & 0 \\
\hline
\end{tabular}


Table 2

Fundamental Frequencies (in Hertz) of Notes in Stimulus Scales and Corresponding Intonation Models

\begin{tabular}{|c|c|c|c|c|c|c|c|c|}
\hline \multirow[b]{2}{*}{ Note } & \multicolumn{3}{|c|}{ Type la Scale } & \multicolumn{3}{|c|}{ Type 1b Scale } & \multicolumn{2}{|c|}{ Type 2 Scale } \\
\hline & $\begin{array}{l}\text { Stimulus } \\
\text { Scale }\end{array}$ & $\begin{array}{l}\text { Pythagorean } \\
\text { Model }\end{array}$ & $\begin{array}{l}\text { Just Intonation } \\
\text { Model }\end{array}$ & $\begin{array}{l}\text { Stimulus } \\
\text { Scale }\end{array}$ & $\begin{array}{c}\text { Pythagorean } \\
\text { Model }\end{array}$ & $\begin{array}{c}\text { Just Intonation } \\
\text { Model }\end{array}$ & $\begin{array}{l}\text { Stimulus } \\
\text { Scale }\end{array}$ & $\begin{array}{c}\text { Equal-Temperament } \\
\text { Model }\end{array}$ \\
\hline $\mathrm{C}_{4}$ fixed & 261 & 261 & 261 & 264 & 264 & 264 & 262 & 262 \\
\hline $\mathrm{D}_{4}$ fixed & 293 & 293 & 293 & 297 & 297 & 297 & 294 & 294 \\
\hline$E_{4} \begin{array}{l}\text { flat } \\
\text { sharp }\end{array}$ & $\begin{array}{l}319-322 \\
334-338\end{array}$ & 330 & 326 & $\begin{array}{l}323-326 \\
337-342\end{array}$ & 334 & 330 & $\begin{array}{l}320-324 \\
335-339\end{array}$ & 330 \\
\hline $\mathrm{F}_{4}$ fixed & 348 & 348 & 348 & 352 & 352 & 352 & 349 & 349 \\
\hline $\mathrm{G}_{4}$ fixed & 391 & 391 & 391 & 396 & 396 & 396 & 392 & 392 \\
\hline$A_{4} \begin{array}{l}\text { flat } \\
\text { sharp }\end{array}$ & $\begin{array}{l}425-430 \\
445-450\end{array}$ & 440 & 435 & $\begin{array}{l}430-435 \\
450-456\end{array}$ & 445 & 440 & $\begin{array}{l}427-432 \\
448-453\end{array}$ & 440 \\
\hline$B_{4} \begin{array}{l}\text { flat } \\
\text { sharp }\end{array}$ & $\begin{array}{l}478-483 \\
506-501\end{array}$ & 495 & 489 & $\begin{array}{l}484-490 \\
507-513\end{array}$ & 501 & 495 & $\begin{array}{l}480-485 \\
503-508\end{array}$ & 494 \\
\hline $\mathrm{C}_{5}$ fixed & 521 & 521 & 521 & 528 & 528 & 528 & 523 & 523 \\
\hline
\end{tabular}

also included two "up" buttons to increase the frequency of the note--one for coarse tuning in steps of $1 \mathrm{~Hz}$, and another for fine tuning in $0.1-\mathrm{Hz}$ increments. Analogously, there were two "down" buttons to decrease the frequency. It was not possible to evaluate a single tone. Keying in the "play" button always triggered the generation of the complete scale. The subjects were allowed to hear the (partially) adjusted scale as often as they wished. Finally, a "next scale" button was provided to call up a new stimulus scale. No knowledge of results was provided. There was no time pressure, and the subjects were able to insert breaks when they desired. Each subject participated for two consecutive daily sessions, lasting approximately $1.5 \mathrm{~h}$ each. Half of the stimulus scales were adjusted at the first session, and half were adjusted at the second session.

\section{Scoring}

Frequency settings were converted from hertz to cents deviation from model scales. In this manner, a positive value indicated sharpening of the setting with respect to the model, and a negative value indicated flattening. Deviations from Pythagorean and just intonations were calculated within the frame of Type 1 stimulus scales, and deviations from equal-tempered intonation were calculated within the frame of Type 2 stimulus scales. To evaluate the accuracy and precision of adjustments, constant error and relative error scores were computed, respectively. The former were defined as the signed deviations from normative frequencies, and the latter were defined as the standard deviations of constant error scores within sets of repeated measurements.

\section{RESULTS}

All the analyses were performed on data pooled over sessions and scale directions: product-moment correlation coefficients between constant error scores and their order of registration revealed no practice effects $(t$ tests always yielded nonsignificant correlation coefficients).

To test for differences between constant error scores in ascending and descending scales and examine the homogeneity of subject groups, analyses of variance were performed for all combinations of stimulus scales and intonation models. The statistical model was a 2 (scale directions) $\times 7$ (or 10 ; subjects) mixed, randomized block factorial design with replications within each treatment combination (Winer, Brown, \& Michels,
1991). Scale direction was considered as a fixed factor, and subjects was defined as random. Since there was no evidence of any interaction between subjects and scale direction, the interaction term was deleted from the linear model and pooled with the experimental error, thus making the $F$ test for treatment effects more powerful. The analyses showed that (1) the constant error scores for ascending and descending scales did not differ significantly, (2) violinists and pianists were homogeneous subject groups, and (3) the group of nonmusicians was heterogeneous ( $p<.05$ in all cases). A posteriori tests for differences (Scheffé) among nonmusicians indicated that 2 of the subjects had lower $(p<.05)$ mean error scores than the other members of the group.

The major findings are shown in Figures 1 and 2. In Figure 1, arithmetic means of constant errors for E, A, and $B$ are plotted for the different intonation models and subject groups. Analogously, in Figure 2, arithmetic means of relative errors for $\mathrm{E}, \mathrm{A}$, and $\mathrm{B}$ are plotted for different subject groups. Note that the data points for Pythagorean and just intonations in Figure 1 are perfectly redundant, since they were calculated from the same scale adjustments. Interval estimates were used because the present study was also concerned with inferring the size of the effect of musical experience on tuning performances, and significance tests are not suited for that purpose. ${ }^{4}$

Figure 1 shows the following:

1. Violinists, pianists, and nonmusicians set $E, A$, and B significantly flatter than their nominal value in Pythagorean tuning. For violinists, the average departure over all trials is only 3.5 cents. For pianists and nonmusicians, the corresponding average departures are 8.9 and 18.5 cents, respectively.

2. Violinists set $\mathrm{E}, \mathrm{A}$, and $\mathrm{B}$ sharp relative to equaltempered tuning. The average sharpening over all trials is 4.8 cents. The nonoverlap between the confidence intervals for $B$ and $A$ shows that the departure from equaltempered tuning is significantly greater for $\mathrm{B}(6.2$ cents $)$ than for $\mathrm{A}$ ( 3.4 cents). The departure from equaltempered tuning for $E$ ( 4.74 cents) is between the de- 
partures for $\mathrm{A}$ and $\mathrm{B}$, and is not significantly different from those departures $(p>.05)$.

3. Pianists virtually do not deviate from equaltempered tuning. The arithmetic mean of constant errors over all trials is only 0.6 cents.

Figure 2 shows that mean relative errors of nonmusicians are significantly larger than those of violinists and pianists.

\section{Discussion}

All the results not directly related to the major purpose of the study were in agreement with expectations and the findings of previous investigations. The fact that no practice effects were found was to be expected because only 24 scales were tuned, and the subjects were either highly trained professionals or inexperienced subjects who received no feedback. It was found that frequency settings were not affected by scale direction, which is in line with studies of actual musical performance (Duke, 1985; Greene, 1937; Loosen, 1993; Mason, 1960).

Turning to the main issues of the present study, the results are consistent with the view that intensive violin or piano playing in the long run creates a preferential bias

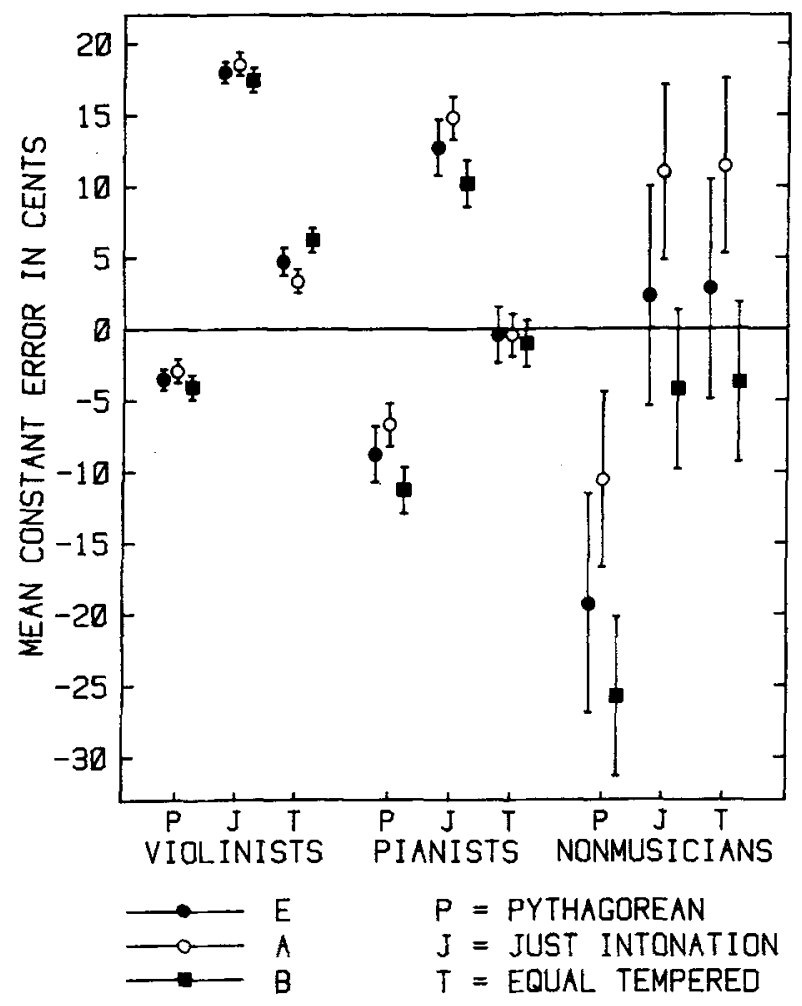

Figure 1. Arithmetic means of departures from Pythagorean, just, and equal-tempered intonations in adjustments of $E, A$, and $B$ in ascending and descending diatonic scales of $\mathrm{C}$ major $\left(\mathrm{C}_{4}-\mathrm{C}_{5}\right)$. Vertical bars represent the $99 \%$ confidence intervals of the means. For violinists $(n=7)$ and pianists $(n=7)$, each plotted point is based on 56 adjustments. For nonmusicians $(n=10)$, each plotted point is based on 80 adjustments.

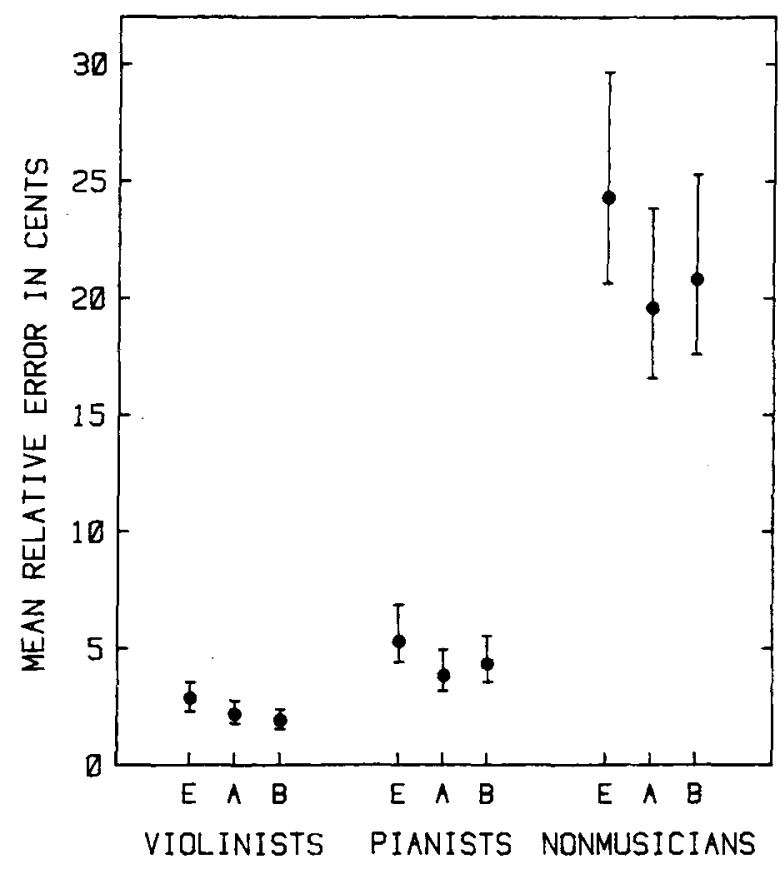

Figure 2. Arithmetic means of relative errors in adjustments of $E$, $A$, and $B$ in ascending and descending diatonic scales of $C$ major $\left(\mathrm{C}_{4}-\mathrm{C}_{5}\right)$. Means were calculated over all stimulus scales. Vertical bars represent the $99 \%$ confidence intervals of the mean relative errors. For violinists $(n=7)$ and pianists $(n=7)$, each plotted point is based on 42 error scores. For nonmusicians $(n=10)$, each plotted point is based on 60 error scores.

for the intonation system to which those instruments are related. (1) Violinists deviate less from Pythagorean intonation than do pianists; (2) pianists fit closest to equaltempered intonation; and (3) nonmusicians do not show any preference for a specific intonation model.

The fact that violinists "play sharp" relative to equaltempered tuning has already been found (Ward, 1970). The present study further specifies that it is not only a matter of setting sharp, but also a matter of shifting toward Pythagorean tuning. Indeed, if the former is true, then there should be no difference in the departure from equal-tempered tuning for $\mathrm{E}, \mathrm{A}$, and $\mathrm{B}$; if the latter is true, then the departure should be greatest for $B$, least for $\mathrm{A}$, and in between for $\mathrm{E} .{ }^{5}$ The "T" judgments of the violinists in Figure 1 show that $B$ is indeed sharped the most relative to equal-tempered tuning, $A$ is sharped the least, and $\mathrm{E}$ is sharped between $\mathrm{B}$ and $\mathrm{A}$.

The present results are also in line with Loosen's (1993) finding that intonation in actual violin performance lies in between Pythagorean and equally tempered intonations. The fact that the violinists" "shift" to the Pythagorean model is not "perfect" is probably due to the fact that they frequently play with piano accompaniment, and it can be expected that in the slower parts they adapt their tuning to that of the piano. In this way, violinists have active experience with equal-tempered tuning. On the other hand, pianists, when accompanying instrumentalists playing variably pitched instruments, 
are used to the instrumentalists' adapting themselves to the piano's tuning. Hence, the intonation model of pianists is preserved intact.

The nonmusicians' ability to tune scales was severely limited. This finding is in line with earlier experiments that showed that naive listeners are incapable of reliably identifying intervals (Siegel \& Siegel, 1977b).

The present study offers no support for the claim that intonation preferences have a natural basis on either mathematical or acoustic grounds (see Meyer, 1956). The results provide no evidence for the simple-ratio hypothesis that tuning performance is determined by an innate preference for small whole-number frequency ratios (Benade, 1976). If innate constraints have brought subjects to prefer musical intervals with small-integer ratios (with reference to the tonic or the preceding note), then, analogously, scale adjustments should have fitted just intonation most closely, because the tones of that model can be obtained by dividing a string exactly into two, three, four, or more equal sections (and bringing them back to the proper octave). In the present study, just as in Mason's (1960) investigation on the performances of woodwind quintets, the musicians deviated clearly from just intonation.

In general, the conclusions of this investigation are supported by the results of various cross-cultural studies showing that musical scales appear to depend heavily upon culturally defined learning experiences (Hood, 1971). Subjects learn the scales of their culture from experience, and not because of any innate propensity of the auditory system (Deutsch \& Feroe, 1981; Dowling, 1978).

Finally, the present study carries some practical implications for the validity of assessment procedures, in which students who practice different instruments are all subjected to the same melodic dictation test. On the basis of intersubject differences in musical experience, it is to be expected that pianists are at an advantage when they are presented with piano tones, and, analogously, violinists are at an advantage when they hear violin tones. Yet, obviously, this hypothesis should be tested empirically in future research.

In the present study, only scales in C major were presented at a particular presentation rate. Consequently, until further investigations are undertaken, whether the conclusions can legitimately be generalized to other situations remains an open question.

\section{REFERENCES}

Algom, D., \& Marks, L. (1984). Individual differences in loudness processing and loudness scales. Journal of Experimental Psychology: General, 113, 571-593.

ALLEN, D. (1967). Octave discriminability of musical and non-musical subjects. Psychonomic Science, 7, 421-422.

BARBOUR, J. M. (1972). Tuning and temperament: A historical survey. New York: Da Capo. (Original work published 1951)

BENADE, A. H. (1976). Fundamentals of musical acoustics. New York: Oxford University Press.

BurNS, E. M., \& WARD, W. D. (1982). Intervals, scales, and tuning. In D. Deutsch (Ed.), The psychology of music (pp. 241-269). New York: Academic Press.
Cornu, A., \& Mercadier, E. (1872). Sur les intervalles musicaux mélodiques. Comptes Rendus Hebdomaires des Séances de l'Académie des Sciences, 74, 321-323.

Corso, J. F. (1954a). Scale position and performed melodic octaves. Journal of Psychology, 37, 297-305.

Corso, J. F. (1954b). Unison tuning of musical instruments. Journal of the Acoustical Society of America, 26, 746-750.

DEUTSCH, D., \& FEROE, J. (1981). The internal representation of pitch sequences in tonal music. Psychological Review, 88, 503-522.

Devie, D. (1990). Le Tempérament musical: Philosophie, histoire, théorie et pratique [The musical temperament: Philosophy, history, theory and practice]. Béziers: Société de Musicologie du Languedoc.

Dowling, W. J. (1978). Scale and contour : Two components of a theory of memory for melodies. Psychological Review, 85, 341-354.

DUKE, R. A. (1985). Wind instrumentalists' intonational performance of selected musical intervals. Journal of Research in Music Education, 33, 101-111.

Elliot, J., Platt, J. R., \& Racine, R. J. (1987). Adjustment of successive and simultaneous intervals by musically experienced and inexperienced subjects. Perception \& Psychophysics, 42, 594-598.

ELLIS, A. J. (1954). Additions to the translation of the book on the sensations of tone by Helmholtz 1885. New York: Dover.

GERINGER, J. M. (1978). Intonational performance and perception of ascending scales. Journal of Research in Music Education, 26, 32-40.

GREENE, P. C. (1937). Violin intonation. Journal of the Acoustical Society of America, 9, 43-44.

Hood, M. (1971). The ethnomusicologist. New York: McGraw-Hill.

LLOYD, L. S., \& BOYLE, H. (1963). Intervals, scales and temperaments. London: Macdonald \& Jane's.

Loosen, F. (1993). Intonation of solo violin performance with reference to equally tempered Pythagorean and just intonations. Journal of the Acoustical Society of America, 93, 525-539.

MARTIN, D. W., \& WARD, W. D. (1961). Subjective evaluation of musical scale temperaments in pianos. Journal of the Acoustical Society of America, 33, 582-585.

Mason, J. A. (1960). Comparison of solo and ensemble performances with reference to Pythagorean, just, and equi-tempered intonations. Journal of Research in Music Education, 8, 31-38.

Mathews, M. V., \& Sims, G. (1981). Perceptual discrimination of just and equal tempered tunings. Journal of the Acoustical Society of America, 69(Suppl. 1), S38.

MEYER, L. B. (1956). Emotion and meaning in music. Chicago: University of Chicago Press.

NICKERSON, J. F. (1949). Intonation of solo and ensemble performance of the same melody. Journal of the Acoustical Society of America, 21, 593-595.

OAKES, M. (1986). Statistical interference: A commentary for the social and behavioural sciences. New York: Wiley.

PARTCH, H. (1949). Genesis of a new music. Madison: University of Wisconsin Press.

Piston, W. (1978). Harmony (4th ed.). New York: Norton.

Platt, J. R., \& Racine, R. J. (1985). Effect of frequency, timbre, experience, and feedback on musical tuning skills. Perception \& Psychophysics, 38, 543-553.

RAKowSKI, A. (1976). Tuning of isolated musical intervals. Journal of the Acoustical Society of America, 59(Suppl. 1), S50.

RoBERTS, L. A., \& MATHEWS, M. V. (1984). Intonation sensitivity for traditional and nontraditional chords. Journal of the Acoustical Society of America, 75, 952-959.

Sharf, B., \& BuUs, S. (1986). Audition I: Stimulus, physiology, thresholds. In K. R. Boff, L. Kaufman, \& J. P. Thomas (Eds.), Handbook of perception and human performance (Vol. 1, pp. 1-71). New York: Wiley.

Siegel, J. A., \& SiEgel, W. (1977a). Absolute identification of notes and intervals by musicians. Perception \& Psychophysics, 21, 143-152.

SiEgel, J. A., \& Siegel, W. (1977b). Categorical perception of tonal intervals: Musicians can't tell sharp from flat. Perception \& Psychophysics, 21, 399-407.

Smal., A. M. (1937). An objective analysis of artistic violin performance. Studies in the Psychology of Music, 4, 172-231. 
Vos, J. (1982). The perception of pure and mistuned musical fifths and major thirds: Thresholds for discrimination, beats, and identification. Perception \& Psychophysics, 32, 297-313.

Vos, J., \& VAN Vianen, B. G. (1985). Thresholds for discrimination between pure and tempered intervals: The relevance of nearly coinciding harmonics. Journal of the Acoustical Society of America, 77, 176-187.

WALKER, R. (1987). The effects of culture, environment, age, and musical training on choices of visual metaphors for sound. Perception \& Psychophysics, 42, 491-502.

WARD, W. D. (1970). Musical perception. In J. V. Tobias (Ed.), Foundations of modern auditory theory (Vol. 1, pp. 420-421). New York: Academic Press.

WARD, W., \& MarTin, W. (1961). Psychophysical comparison of just tuning and equal temperament in sequences of interval tones. Journal of the Acoustical Society of America, 33, 586-588.

WinER, B. J., Brown, D., \& MicheLs, K. E. (1991). Statistical principles in experimental design (2nd ed.). New York: McGraw-Hill.

\section{NOTES}

1. The equal-tempered scale is unequivocally defined by 12 equal logarithmic steps (semitones), each representing a frequency that is $2^{1 / 12}$ times greater than the one below. The inclusive set of 12 adjacent semitones within an octave (i.e., the interval between two frequencies having a ratio of 2:1) is referred to as the chromatic scale. Most compositions in Western music do not employ all of the intervals of the chromatic scale, but are based instead on seven-interval subsets of the chromatic scale. A diatonic scale consists of seven tones separated by an invariant sequence of intervals of $2,2,1,2,2,2$, and 1 semitones. Each diatonic scale is identified by the note that acts as tonal center, called the keynote (or tonic). For the major mode, the keynote is the first note. Hence, in the diatonic scale of $C$ major, the first note is $\mathrm{C}$ (see Piston, 1978, for more details).

There are model scales in which the 12 adjacent intervals of the octave are not all of equal size. Two important representatives are the
Pythagorean scale and the just intonation scale. In this paper, the labels "Pythagorean" and "just intonation" stand for Ptolemy's diatonic ditoniaion and Ptolemy's diatonic syntonon, respectively. The major mode of the former is defined as one in which the ratios of the frequencies of adjacent notes from the tonic are 9/8, 9/8, 256/243, 9/8, $9 / 8,9 / 8$, and $256 / 243$. Analogously, the major mode of the just intonation scale is defined by the ratios $9 / 8,10 / 9,16 / 15,9 / 8,10 / 9,9 / 8$, and $16 / 15$ (for a detailed description of how these series are generated, see Barbour, 1951/1972, chap. 2).

2. Pianos are tuned in a "stretched" scale (i.e., upper tones are higher and lower tones are lower than in the equal-tempered scale). However, departures from the equal-tempered intonation can be neglected in the middle range of the piano scale (Martin \& Ward, 1961).

3. A cent is a unit of interval measure equaling the 1,200 th part of an octave. Therefore, if $f_{1}$ and $f_{2}$ are the frequencies of, respectively, the lower and upper limit of an interval, then the interval size in cents is defined as $1,200 \log _{2}\left(f_{2} / f_{1}\right)$.

4. Confidence intervals provide both a measure of the size of the effect and an unequivocal basis for statistical decisions (Oakes, 1986). To reject the hypothesis that a parameter equals a constant value, it is necessary and sufficient that the value does not fall within the confidence interval. Analogously, the nonoverlap between two confidence intervals can be used as a criterion for significance. In the present context, this conservative test seemed appropriate because a speculative hypothesis was tested. In a simulation experiment, in which 100,000 times two samples of size $n=56$ (i.e., the number of observations on which the plotted points for violinists and pianists are based in Figure 1) were chosen from the same population, the probability of a Type I error was .005 when the nonoverlap of the $95 \%$ confidence intervals of the means was used as a criterion for a significant difference between the two means.

5. The author is indebted to W. Dixon Ward for bringing this argument to his attention.

(Manuscript received April 23, 1993 ; revision accepted for publication January $25,1994$. ) 